side of the water who would be called a gamekeeper at home?

While we may regret the manner in which the author has gained his information, we may concede that he has written an interesting account of the animals he has hunted, though always from the standpoint of a sportsman. Of these the wapiti (Cervus canadense), the antelope-goat (Haplocerus montanus) and the bighorn (Ovis montana) appear to have constituted his favourite prey, and are consequently most fully described and illustrated.

In the chapter on seals, Mr. Grohman condemns pelagic hunting in unmeasured terms :-

"Pelagic sealing is a cruel and most wasteful method of obtaining peltry which can be secured by 'land killing' at the rookeries without inflicting suffering and without any appreciable waste. Those who dispute this do so either from ignorance of the true facts or from interested motives" (p. I92).

Regarding the salmon of the Pacific Slope, he has the same black record to make of reckless waste and rapidly diminishing resources, stating, on the authority of a Canadian Blue Book, that at one of the Alaskan canneries "in one day $2 c, 000$ fish, of an average weight of ro lbs. each, were thrown away because of the inadequate appurtenances of the establishment and the suddenness of the run" (p. 222).

In the later chapters of his book Mr. Baillie-Grohman gives an entertaining account of his rough and varied experiences as a pioneer in Kootenay, where, among other matters, he was himself hunted and nearly shot by a lawless prospector who had a grievance against him. Mr. Baillie-Grohman took up from the Provincial Govern. ment an extensive concession of lands subject to summer floods in the Lower Kootenay valley, and his scheme for the reclamation of these lands affords a striking commentary on the abnormal relations which exist between the main valley system and the present drainage of this region. The physiography of the mountainous country westward from the Rockies to the ocean abounds in anomalous characters which are as yet for the most part unexplained, offering many magnificent problems for the student of the evolution of land-forms; and of these none is more remarkable than the case in question.

The Columbia river, rising in Columbia Lake, flows at first north-westward and afterwards southward, throwing a loop of masnificent proportions northward around the Selkirk Range; while its great tributary, the Kootenay, makes a similar but diametrically opposite loop southward, crossing the United States boundary line into Montana and Idaho, and then recrossing to reach its confluence with the Columbia; and the two rivers thus encircle a huge oval tract of mountains over 300 miles in length. Now, the Kootenay some 80 miles below its source swings into the depression which contains the Columbia Lake, only one mile distant from it, but flows thence southward away from the lake. Mr. BaillieGrohınan's plan was simply to make the circlet of waters complete by turning the Kootenay into the lake.

"The piece of land lying between the two waters was a level stretch of gravel shelving from the river to the lake, the latter being about in feet lower than the Kootenay. With such a fall in less than a mile it practically needed very little work, for, once a big ditch was cut, the rushing Kootenay, at that point a rapid stream some 300 feet wide, would do the rest. By turning off such a large quantity of water it was expected that the overflow of the bottorn land 300 miles further down would be prevented. It was really restoring things to their original condition, for there is no doubt that a comparatively short time back the Kootenay river forked at the Canal Flat, the northern branch flowing over the flat where I proposed to make the canal, while the southern occupied its present bed" (p. 26r).

No. I 589 , vOL. $6 \mathrm{I}]$
But rival interests were involved. The Canadian Pacific Railway had been planned to run along part of the Columbia valley just ahove high-water mark, and its authorities took alarm at the possibility of a vast increase in volume of the river, and prevailed upon the Federal Government to stop the scheme. The upshot, as told by $\mathrm{Mr}$. Baillie-(irohman, is by no means to the credit of the Dominion and Provincial Governments. And thus the waters of the Columbia and Kootenay, after so nearly embracing in their youth, have still to make their separated journey of, together, nearly 800 miles before they unite in full maturity.

In his rendering of the colloquial slang of the West, Mr. Baillie-Grohman is not particularly happy. The examples he gives are generally overdone, the really vigorous expressions being weakened by being crowded in unwarranted sequence. When he defines a "rustler" as being synonymous with a pilferer, he is decidedly mistaken (pp. 276-8). The "rustler" is a man of energy and resource, one fit for any emergency - a man who, in Western parlance, "could hang himself up on a nail to sleep," and there is no opprobrium implied in the term. The point is of some importance, as a stranger to the country, following Mr. Baillie-Grohman's usage of the word, might unwittingly give serious offence.

The illustrations of the book, reproduced from excellent photographs, deserve praise. They have been selected to show the character and conditions of the country as well as its animal life, and serve this purpose well, though they are not always strictly applicable to the text.

G. W. L.

\section{EUGENIO BELTRAMI}

$\mathrm{BY}^{\mathrm{Y}}$ the death, on February 18, of Prof. Eugenio Beltrami, after a long illness followed by an unsuccessful surgical operation, Italy has lost a mathematician who did much to bring his country to the forefront in the mathematical world almost simultaneously with the ascendancy of Italy. in the world of politics.

Eugenio Beltrami was born at Cremona on November I6, I835, of a well-known and highly-cultured Italian family. After completing his school curriculum in his native town, he went to Pavia, and then studied mathematics for three years under Brioschi. For some years Beltrami had to earn his own living, and an appointment in the Administration of the Italian Railways, which he held first at Verona, and then at Milan, if it afforded him no scope for his mathematical abilities, at any rate furnished him with the means of subsistence. At Milan, in 1860 , Beltrami became acquainted with Cremona, whose influence, combined with a study of the works of Gauss, Lagrange and Riemann, opened the way for his development of higher geometry, in which branch of mathematics Beltrami published his first papers, in 1862 , in the Annali di Matematica.

In the same year he was appointed professor extraordinarius in algebra and analytical geometry at Bologna, and in the following year he became professor ordinarius of geodesy at Pisa, where he enjoyed the friendship of Riemann and Betti. In 1865 , Beltrami returned to Bologna, where he occupied the chair in rational mechanics. Two years later appeared what has been aptly regarded as Beltrami's masterpiece, the "Saggio d'interpretazione della geometria non euclidea," published in the Giornale matematico di Napoli. We learn that Beltrami's attention was first attracted to this subject by an observation of Lagrange on maps, in which geodesics are represented on a plane by straight lines, and was thus led to consider the properties of surfaces on which the geodesics are represented by linear equations in curvilinear co-ordinates. Beltrami found that such surfaces were the same as surfaces of constant curvature. 
He was thus led to examine the properties of the surface of constant negative curvature, to which he gave the name of pseudosphere, and the geometry of such a surface was found to be identical with the geometry of Gauss and Lobatschewsky. As his old pupil and successor at Pavia, Prof. Carlo Somigliana, remarks, "It can thus be said that although the germs of his results can be traced back to some of his predecessors, and, in particular, can be found in the profound considerations of Riemann, and other advances have come subsequently, yet his work represents and synthesises the most decisive step that has been made in modern times by the geometric conception of real space."

Nor was the "Saggio d'interpretazione" by any means Beltrami's only contribution to mathematical literature at the period under consideration. We find him extending the properties of surfaces of constant curvature to $n$ dimensional space; and his papers on differential parameters, on the flexure of ruled surfaces, and on the general theory of surfaces, published a few years previously to the "Saggio," are well known to mathematicians.

In 1873 , Beltrami migrated to Rome as professor of rational dynamics and higher analysis, and was elected a Fellow of the Italian equivalent of our Royal Society, the Reale Accademia dei Lincei. His sojourn in Rome was of brief duration; for, much to the regret of his friends there, he went to Pavia in 1876 , where he lectured on mathematical physics and higher mechanics, and it was not until 180 that an opportunity offered itself for him to return to Rome. It was only two years ago that Beltrami was prevailed on to accept the office of President of the "Lincei," and last year he was unanimously elected to the senatorial rank. As a general rule, however, he avoided all public appointments, and the only other post he held was on the Italian Council of Education. He preferred to devote his entire energies to the studies in which he was interested, and sought no scientific distinctions; still, the laurels which he had well earned were freely showered on him by the academies of Bologna, Lombardy, Turin, Naples, Paris, Göttingen, Brussels, Munich and Berlin ; and the London Mathematical Society was also proud to place his name on its list of foreign mathematicians.

We have hitherto spoken chiefly of Beltrami's work as a pure mathematician, but his later investigations tended more especially in the direction of applied mathematics. Hydrodynamics, theory of potential, elasticity, physical optics, electricity and magnetism, conduction of heat and thermodynamics were all made the subject of papers, each of which "shed a bright light on some difficult or controversial point." In the theory of the potential considerable simplifications of method were made, and the papers on potentials of symmetric distributions and on the attractions of ellipsoids are described by Somigliana as "true models of classical elegance." In the theory of elasticity, Lamé's equations'were shown to be intimately related to the euclideity of space, and the generalisations for spaces of constant curvature opened up a new field for research, of which Beltrami endeavoured to make use in accounting for the uncertainties in Maxwell's theory, which substitutes action in a continuous medium for action at a distance.

The last period of his researches was devoted to developing Maxwell's theories of electro-magnetic phenomena, a difficult task, for which Beltrami's mathematical knowledge well fitted him. All who have read Maxwell's treatise realise that it contains many obscure points and demonstrations of hardly a rigorous nature, and most of those who have failed to follow his arguments have preferred to regard the results as statements of Maxwell's views, rather than inquire into the validity of the reasoning on which they were based. Beltrami, on the other hand, being well versed in the art of exact expression and the elegances of neatness of analytical form, was not contented with Maxwell's rough-and-ready methods, but devoted long hours of deep thought to co-ordinating and perfecting the ideas which he regarded as incomplete. Among his latest contributions to the Atti dei Lincei we notice a paper on thermodynamic potentials published in 1895 .

As a professor, Beltrami's lectures are said to have been characterised by the same perfection of style and exactness of form which are so conspicuous in his writings. His genial manner and high culture made him a centre no less in general society than in the scientific world. Shakespeare's epithet, "Cunning in music and in mathematics" well applies to Beltrami, and we learn from Signor Pietro Cassani's obituary address to the Venetian Academy, that having been taught music in his early days by his mother, and afterwards under Ponchielli, he would often delight his friends by his renderings on the piano of the masterpieces of Bach, Mendelssohn and Schumann.

The life that has been brought to such a sad close must have been in many respects an ideal life. Beltrami had every opportunity for devoting himself to the studies which he chose as his life's work ; he knew nothing of rivalries and petty jealousies, as he made no enemies; but, on the other hand, we cannot but suppose that his experience of the necessities of making the best of somewhat uncongenial surroundings during his years of railway work had a beneficial influence on his after life, in preventing Beltrami from attempting to live up to a false ideal. His loss adds another to the many gaps in the mathematical world, but his published works form a fitting memorial of their author, and several of them bid fair to be handed down to posterity among the mathematical classics.

We are indebted to Prof, Blaserna, of Rome, for much valuable information on which this account is based.

G. H. BRYAN.

\section{PROF. ST. GEORGE MIVART.}

$\mathrm{BY}$ the sudden death, at the age of seventy-two, of Prof. St. George Mivart, the world in general and science in particular are distinctly the poorer. For he was essentially a many-sided man; and although an energetic and accurate investigator in several branches of biology, was in no sense a specialist whose efforts were restricted to the elucidation of abstruse facts or the elaboration of theories in which the general public could take little or no interest. On the contrary, ever since I 870 , when he first began to contribute to the higher grade of popular reviews, he has kept himself constantly in evidence, and has thus become known to a very wide circle of readers, especially as the apostle of the evoltution of organic nature under divine guidance.

St. George Mivart was born at his father's house in Brook Street, Grosvenor Square, on November 20, 1827. $\mathrm{He}$ was educated successively at Clapham Grammar School, Harrow, King's College, London, and St. Mary's College, Oscott; his adoption, in 1844 , of the principles of the Romish faith being at that time a bar to his matriculating at Oxford, where it was his father's intention that his education should have been completed. In 1851 he was called to the Bar at Lincoln's Inn, but his legal career, if he ever practised at all, was a brief one ; and in a short time his attention was concentrated first on medical and later on biological studies. By 1862 Mivart had made such a reputation in medico-biological studies that he was appointed a lecturer at the Medical School of St. Mary's Hospital. Previously to this, in 1885, he became a Fellow of the Zoological Society, of which body he was elected a Vice-President in 1869 , and again in 1896 ; indeed, he continued in the latter office

No. 1589 , voL. 6I] 